\title{
Untangling Barriers in Knowledge Management: A Case Study on the Department of Commerce, Yangon University of Economics (YUECO)
}

\author{
Win Moe Moe Kyaw*, Khine Tin Zar Lwin \\ Department of Commerce \\ Yangon University of Economics \\ *Corresponding author: chawchithsu@gmail.com
}

\begin{abstract}
Knowledge Management (KM) is known to be key to the long-term management success of knowledge-based units. In educational settings, $\mathrm{KM}$ is the effective of information to improve the use and sharing of valuable knowledge and information flow. Effective knowledge management practices are defined by acquisition, retention, and sharing, amplifying staff and students' teaching and learning abilities. However ,KM barriers tend to persist, and the presence of barriers impedes the attainment of objectives in educational setting. In particular, while the academic research on KM barrier is available in other manufacturing indsury such as IT (Karamat et al., 2018), to the best of our knowledge the topic of KM barriers concentrated in education is a scarcity in published research studies (Veer Ramjeawon \& Rowley, 2017), and the empirical study has never done before for the departmental level including in Myanmar. Therefore, this study aims to uncover the barriers of each micro-KM practice in an academic department. An exploratory case study was conducted by interviewing seven participants who are academic staff in the Department of Commerce, Yangon University of Economics. The participants revealed that individual factors underpin knowledge acquisition, organizational factors impact knowledge retention, and both individual and organization-level barriers manifest in the knowledge sharing process. Therefore, it is advocated that resources such as time, space, and autonomy for individual knowledge creation, as well as cultural intervention, are requisite for fostering an atmosphere of knowledge sharing at the departmental level. As research contribution, effective knowledge management practices can improve the current situation of the department because it can have a great impact on the departmental outcomes and performance, which in turn leads to the objectives of teriatory education.
\end{abstract}

Keywords: Barriers, Education, Knowledge Management Practices

\section{Introduction}

Knowledge has become an essential resource for all organizations, including educational institutions, to attain goals. Education is one of the most important contributing factors in developing and prospering a nation, as it helps people gain valuable knowledge. In addition, it leads to flourishing national development and advancement of society. Accordingly, many countries around the world have been paying significant attention to the effective implementation of knowledge management (KM) in their educational settings. KM is defined as a process consisting of three practices, such as knowledge acquisition, retention, and sharing to enhance organisations' long-term performance (Davenport \& Prusak, 2000). In the educational setting, the role of (KM) is particularly 
critical (Petrides \& Nodine, 2003). Knowledge is a valuable resource for knowledge workers, who are academic staff, as these people deploy their brains more than their muscles to create values and to enhance innovations in teaching and learning activities (Mládková, 2011). As knowledge workers create values in knowledge-based units, such as universities or departments within universities, a sizable emphasis has been given to knowledge management as a facilitated tool for creating, retaining, and sharing knowledge (Nair \& Munusami, 2019). KM engenders a mind-set in an individual to enable the continual acquiring, retaining, using, and sharing of knowledge. Baskerville and Dulipovici (2006) proposed that KM is a fascinating way to develop rapid practical intellectual strength for management.

Via facilitating the continuous learning of all organizational members and departments, $\mathrm{KM}$ is instrumental for enhancing the teaching and learning of students and academic staff in tertiary institutions (Oakley, 2003). This means that using KM systems and principles, academic departments and educational institutions can create more flexibility in decision making, promote teaching and learning processes, improve teachers' research skills, create an effective internal and external communication network, increase faculty knowledge, and improve quality and quantity of research activities. Its effective implementation can capture the potential benefits of KM practices such as magnifying the staff and students' teaching and learning abilities and attaining organizational goals.

Although the underlying benefits of $\mathrm{KM}$ in educational institutions are substantive, effective implementation of KM is hard to realize (Verespej, 1999) since organizations, including sub-units such as departments, inevitably encounter inherent challenges in implementing effective KM practices (Nadason, Saad, \& Ahmi, 2017). In general, according to Kalkan (2005), KM barriers or challenges facing by organizations today are how to deal with tacit knowledge, utilize IT, develope new organizational culture, and organizational structures. The educational institutions, such as academic departments are constantly exposed to key challenges in KM implementation (Khakpour, 2015). Therefore, it is intriguing to explore the underlying barriers that reside in each micro process of the KM. Understanding key barriers and challenges in $\mathrm{KM}$ implementation can facilitate removing underlying barriers at each stage of the KM process and assure the intended benefits of KM practices such as enhancing students' teaching and learning abilities and attaining institutional goals. Theoretically, to an organization, KM challenges are presented at all levels, such as organizational or individual. At a border level, the national culture and filed level differences (such as private and public, IT, and hospitality) can also shape KM challenges. The challenges such as the creation of new knowledge and refinement of existing knowledge can have far-reaching impacts on enhancing teaching and learning abilities and obtaining the objectives of tertiary institutions. Therefore, key barriers and challenges to KM implementation need to be identified to design the strategies that can minimize KM obstacles for effective KM within an academic department.

The purpose of this study is to untangle the barriers impeding the micro-KM processes in an academic department, i.e., the Department of Commerce in the Yangon University of Economics, to offer implications to enhance the teaching and learning abilities of academic staff and students also as well as assist the attainment of a tertiary institution. 


\section{Literature Review}

According to Drucker (1993), knowledge can be defined as the most valuable asset for an organization to retain sustainable competitive advantage (Holsapple, 2003). It is imperative to distinguish between the concepts of data, information, and knowledge. In this regard, Wallace (2007) explained that data is a general concept that refers to the fact, whereas information is a set of data that has been endowed, processed and interpreted. While information provides meaning and purpose through interpreting data, knowledge is information that involves the experiences that help people accumulate data and information in a meaningful way. As Gammelgaard and Ritter (2000) state, knowledge has been recognized "as a combination of experience, values, contextual information, and expert insight that help evaluate and incorporate new experience and information" (as cited in Sabri, 2012, p. 8).

In a similar vein, Haggie and Kingston (2003) point out that organizations cannot survive and thrive in a knowledge-based society unless they have a successful KM strategy to create new knowledge and leverage their intellectual capital. According to Swan (1999), "knowledge management is about harnessing the intellectual and social capital of individuals in order to improve organizational learning capabilities, recognizing that knowledge, and not simply information, is the primary source of an organization's innovative potential" (as cited in Abebe, 2016, p. 3).

For educational organizations, Hislop (2013) reports that "KM is considered to be an effective way to enhance the creation and sharing of knowledge within the organization. It consists of individuals collaborating to acquire knowledge suitable for the educational organizations to enhance educational programs and professional development" (p. 13). The main objective of KM is to create the right knowledge, that refers to new knowledge available to give better presentations at the right time for the right reasons (Allard, 2004). As Nonaka and Takeuchi (1995) state, organizational knowledge is frequently categorized into two different types: tacit and explicit knowledge. Tacit knowledge can be defined as action-based, including personal emotions, experience, and judgment, so that it cannot be easily explained or formulated (as cited in Gourlay, 2003).

In educational settings, tacit knowledge includes the knowledge related to subject areas and working practices that are not easily transferable but are stored in individual staff members (Nonaka \& Konno, 1998). In this regard, transfer of such knowledge to other members seems to be the primary concern of knowledge on which organizational knowledge can be developed and maintained becasue tacit knowledge can be transformed into comprehensible forms, allowing it to share with others (Nonaka \& Konno, 1998). Explicit knowledge, unlike tacit knowledge, can be expressed, classified, organized, and recorded; therefore, more easily communicated and shared within the organization (Nonaka \& Konno, 1998). In sub-units, i.e., departments of educational institutions, explict knowledge is knowledge which can be codified, carried, and stored in some form of repositories as members come and go. Tacit knowledge, like experienes and talent of indiviudals, is difficult to codify, thus cannot be managed and shared with other members when these people leave the organizations (Mahroeian \& Forozia, 2012). 


\section{KM Process}

From an organizational learning perspective, $\mathrm{KM}$ is a set of practices to enrich organizations, including the processes required to manage knowledge effectively (Singh, 2009). KM is the management of knowledge through a systematic and organizationally specific process for knowledge acquisition, retention, and sharing, including tacit and explicit knowledge, to enhance organizational performance and thrive long term (Davenport \& Prusak, 2000).

Knowledge Acquisition: Knowledge acquisition/creation is an important activity for an organization's operations that strive to drive the organization to achieve its goals by spreading knowledge creation and innovation (Allard, 2004). In addition, McInerney (2002) has acknowledged that knowledge creation is an essence of KM as it has emerged by creating, capturing, and sharing knowledge within organizations. Nonaka and Takeuchi (1995) developed a dynamic model, the SECI model of knowledge conversion, that explains the process of interactions between explicit and tacit knowledge (as cited in Nonaka \& Konno, 1998) as essential for knowledge creation. The main purpose is to understand where, what, and how knowledge is created and generated and utilize knowledge effectively and efficiently. The model explains socialization (tacit to tacit), externalization (tacit to explicit), combination (explicit to explicit) and internalization (explicit to tacit) (Nonaka, Toyama, \& Konno, 2000).

Knowledge Retention: After creating new knowledge and new concepts, knowledge retention is an integral part of the organizational learning process, as well as a core component of the concept of organizational memory, in order to maximize its long-term reusability and stop the problem of duplication of effort, which wastes time and resources. For instance, O'Toole (2004) states that knowledge retention structures have recognized the importance of capturing knowledge in the organization to respond to impending knowledge loss, and they have highlighted semantic, episodic, and procedural memory. Semantic memory refers to known facts, recall of general facts, and explicit structures such as databases, reference books, and journals, while episodic memory refers to recalling personal facts, personal lived experience, learning histories, annual reports, and organization stories. Procedural memory is a type of long-term memory, including performing routine processes, procedures, skills, and habits (O'Toole, 2004). In addition, Schmitt, Borzillo and Probst (2012) stated that "knowledge is retained in various 'human' and 'non-human' repositories on specific organizational levels" (p. 54).

Knowledge Sharing: Knowledge sharing is also important in order to create awareness amongst the people in the organization. King (2009) states that shared knowledge is utilized to enable an organization to improve innovation capacity, facilitate collective learning and individual learning and enhance collaborative problem-solving. Furthermore, Ben-Peretz and Schonmann (1998) state that communities of practices are part of KM strategies for knowledge sharing as they are formed by groups of people interested in sharing information and discussing a particular topic of common interest to them. They value communal reflection, interact regularly to learn how to do it better, and engage in the process of collective professional learning to develop themselves personally and professionally and sustain school improvement. This is because a community of practice is built on professional networking, personal relationships and shared knowledge, acquiring, sharing, using and retaining knowledge to secure institutional memory and continuity, and sustaining a learning community of teachers 
(Ben-Peretz \& Schonmann, 1998). In addition, Pan and Leidner (2003) state that the use of information technologies facilitates knowledge sharing and the re-use of the obtained knowledge and assists in processing knowledge.

\section{Barriers in KM practices}

Although KM is critical to knowledge creation, retention, and sharing in knowledgebased organizations, there are several barriers faced in the process (Khakpour, 2015). Hence, to implement successful KM, organizational barriers and challenges present in an organization need to be reduced (Bonaventura, 1997), as they would negatively impact staff attitudes towards knowledge sharing and perception about knowledge management success (Choi, 2000).

Major obstacles and barriers to practicing KM are individuals, organizational barriers, technology, and culture (Nadason, Saad, \& Ahmi, 2017). Riege (2005) highlighted that individual barriers to effective $\mathrm{KM}$ are lack of time, low level of consciousness, varying levels of experience, a lack of solid interpersonal skills, weak communication skills, and education. Regarding organizational barriers to KM practices, most of these barriers result from poor leadership skills, insufficient rewards, infrastructure shortages, talent and resource deficiency, and poor communication skills. As far as technology challenges are concerned, lack of knowledge of technology, lack of technical services or support/training in regard to information technology (IT), and unwillingness to use IT systems could be major barriers to effective KM practices.

According to Jarnagin and Slocum (2007), organizational culture is also a critical factor because it influences organizational behaviour. Thus, cultural barriers have become the major concentration for all organizations. They emphasize the importance of organizational daily practices that could be embedded into the organization's culture because high performance is a result of a strong culture. In addition to that, Al-Alawi, Al-Marzooqi and Mohammed (2007) point out that factors such as interpersonal trust, effective organizational communication, motivation, and stimulation of individuals are vital to create a continuous learning culture for KM implementation. Therefore, if an organization cannot strive to embed effective KM practices into its culture, organizational culture could be a major obstacle (McDermott \& O'Dell, 2001).

In educational systems, as stated in Khakpour's (2015) study, some activities designed to enable knowledge exchange among knowledge-workers are problematic since some teachers are not willing to co-operate and share their knowledge with others. This could be because their strong reputation which resulted in a vast store of knowledge is valuable. On the other hand, some may find they are unable to find an adequate way of transferring their knowledge to their colleagues (McCune, 1999).

Bonaventura (1997) claims that rigid regulatory strategies, lack of proper incentive or reward system for cultivating creativity and lack of comprehensive budget and funding can be challenges in implementing KM. In academic settings, knowledge challenges could be categorized into two groups: internal challenges and external challenges (Khakpour, 2015). Khakpour (2015) states that KM's internal challenges are research subsystems, technical subsystems, administrative subsystems, human resource subsystems, students' activities, and structure subsystems. Challenges based on research subsystems include lack of trust as a barrier for consenting to research, inconsistency between studies conducted in different regions, and lack of significant overlap between different cultures (lack of construct or conceptual equivalence). Internal technical 
challenges include a lack of appropriate technology for KM, the inability of technology to cope with the process of tacit knowledge transfer, and a lack of strategies to manage KM. Challenges of administrative subsystems concern lack of participation by some education stakeholders in $\mathrm{KM}$ and challenges in managing experiences and tacit knowledge. Challenges associated with human resource subsystems consist of lack of fair rewards and recognition system that helps motivate employees to share knowledge and lack specific guidelines and criteria to determine worker productivity. Moreover, there are some challenges associated with student activities, including poor integrated management, lack of purpose in knowledge construction, less consistence in content knowledge, and misusing other people's words or the possibility of plagiarism. In terms of facing the challenges in structure subsystems, this includes a lack of appropriate organizational structure, emphasis on a highly formalized form of explicit knowledge and inattention to construct tacit knowledge due to hard and rigid structures. External challenges can include the dominance of the materialist view, globalization and cultural challenges (Khakpour, 2015). Due to the materialist view's dominance, applying business models to higher education is one of the external challenges, including concerns about cost and concerns about student outcomes. Therefore, educational organizations need to understand the challenges or barriers to $\mathrm{KM}$ in order to overcome them and improve the efficiency and effectiveness of the KM processes.

\section{Methodology}

The case study research method was chosen due to the nature of the research objective being examined, i.e.to untangle the barriers pertaining to each micro KM process at subunit level (department). It can investigate an individual circumstance through collecting in-depth data or verifiable data about the individual entity. A single case method was selected (Yin, 2003). More specifically, the authors' department was chosen as a single case for the investigation. While a single case study clearly limits the generalizing of the study's outcomes in terms of applicability to other settings, i.e. other departments (Eisenhardt, 1989; Yin, 2009), the selection of this method is justified due to focal research interest in a particular setting for the phenomenon under study, i.e. Department of Commerce, Yangon University of Economics (Yin, 2003).

A purposeful sampling strategy was taken as the most appropriate sampling due to the complexity of the phenomenon under study (Eisenhardt, 1989). The use of this method would able to identify the richness of data relating to knowledge management barriers which are experienced by individual members of academic institutions (Patton, 2002). This method involves the identification and selection of individuals who are knowledgable to the phenomenon of interest, i.e., barriers in knowledge management in a academic instiution (Cresswell \& Clark, 2011). Seven academic staff (lecturers) from Department of Commerce from YUECO were chosen. An in-depth interview method was carried out during the June, 2020, and each interview was lasted for 30 minutes. The interviews were all audio-recorded and later transcribed. 


\section{Brief Description of Commerce Department, YUECO}

The Yangon University of Economics is the state-owned university as well as the premier university of economics in Myanmar. The university's vision is "To provide quality educational services, ensuring the quality of our students". It has five major teaching departments: Economics, Applied Economics, Statistics, Commerce, and Management Studies. The focus of this case study, the Department of Commerce employs a total of 40 academic staff. The department is organized with the Professor as Head of Department, Associate Professors, Lecturers, Assistant Lecturers, and Tutors. Generally, in line with objectives set forth for the university level, the department's main objectives are to make contributions to the teaching efforts of the University and carry out professional activities and teach the subjects related to management and accounting in postgraduate programs, undergraduate programs and diploma programs. In addition, the academic staff's duties and responsibilities are continuous learning of updated texts and materials, sharing knowledge with students during lectures, assisting with the management course detail, participating in regular meetings, and in-house training programs as part of human resource development, and conducting periodic departmental research. Thus, both tacit (judgement, emotions and experience) and explicit (words and numbers) knowledge are key assets within the department. KM is critically important to acquire, retain, use, and share knowledge to promote departmental goals and objectives.

\section{Current status of KM within the Department}

The participants of the study illuminate the context-specific nature of three of KM processes. Each of the steps of KM is briefly described below. Regarding knowledge acquisition, three different modes of acquisition revolve within the department: external, internal and self-directed. Training, seminars and workshops are the most commonly mentioned external source of knowledge in the knowledge acquisition process. In regard to internal knowledge acquisition, this occurs top-down, bottom-up and laterally. In topdown and lateral internal acquisition modes, much of the knowledge is tacit, and thus there are time and space constraints in a formal transfer of knowledge within the department. To participants, much of the knowledge is acquired utilizing informal socialization with other senior staff and colleagues of the same position who are knowledgeable in the area. Class discussions are also mentioned as a fertile ground for the acquisition of knowledge, where participants can learn new knowledge in areas relating to student projects and assignment, providing an example of the bottom-up approach. While the internal mode is an important source of knowledge acquisition, selfdirected learning also plays an indispensable role in learning new things, to expand existing knowledge and unlearn knowledge becoming obsolete.

Knowledge retention occurs through the process of storage and retrieval of knowledge acquired from the memory of the department. According to the participants, tacit knowledge is retained through the assistance of both traditional and emerging technology. In order to retain tacit knowledge of an expert, the expert's decision making process or knowledge is made visual knowledge representation or documentation. Explicit knowledge, which is part of procedural knowledge, is recorded in paper-based documents and stored in traditional storage places such as cupboard and shelves. While modern organizations are moving into paperless and more IT-based systems, most types 
of explicit knowledge are easily transferable, stored in IT devices such as clouds and Dropbox, retrievable at any time.

Knowledge can be acquired through shared experience, seeing something, observation or hearing and working and learning with others. Knowledge sharing within the department seems to occur mainly though informal means, and socializaiton is the primary mode of knowledge sharing among individual members (Morrinson, 1993). While time constraints limit formal knowledge sharing, informal socialization among the staff of close relationships is the most prevalent means, according to the participants. People in close social relationships shared the valuable knowledge they possess because their relationships foster trust, enhance cooperation, and induce valuable resources, such as knowledge, within organizational members. With regards to the current state of knowledge sharing practices in the department, knowledge is shared with and transferred to others both within and outside the department through conversations with colleagues, sharing knowledge and teaching experience or methods, dealing with difficult students or situations, and preparing tests, exams, and worksheets.

\section{Findings}

\section{Barriers in $K M$}

As a department of a public tertiary education institution of a country in transition, inherent challenges throughout the department's KM process do exist. These challenges are embodied in hierarchy and interdependence. The following section explains the hierarchical nature of challenges that reside in each step of the KM process.

\section{Barriers in Knowledge Acquisition}

Issue 1: The most salient barriers in knowledge acquisition processes are the resources. These resources at both individual and organizational levels seem to have important implications on knowledge acquisition processes within the organizational sub-units. The major barriers in knowledge acquisition pertain to time and physical resource constraints. The limited physical resources, such as the lack of updated textbooks inhibits the speed and quality of knowledge acquisition of individual staff members. For example, Participant A highlights the prevalence of this issue and how it inhibits his/her knowledge acquisition and restricts the creation of new knowledge and his/her potential of sharing with others. As he/she claimed:

As you know, perhaps due to lack of sufficient funding, most of the times, what we have access are books of older editions. While they are extremely useful), at times, I cannot obtain updated books I want by the time I need them. This inability to update books prohibits the process that I am acquiring the knowledge and thus hampering the reproduction of new knowledge that I can otherwise share with my students.

Issue 2: Time constraint is another barrier to knowledge acquisition. The scarcity of time which can be allocated to acquire necessary knowledge limits the entire chain of the KM mechanism, from upstream knowledge acquisition to downstream knowledge sharing. According to participants, insufficient time for devotion to knowledge acquisition is a mere reflection of burdensome work allocation that stems from 
inadequate staff numbers within the unit. The workload being assigned tends to restrict the ability of the members to acquire knowledge within the organization, which is directly applicable to their job. Participant $\mathrm{D}$ provides the following commentary:

All staff in the department are fully occupied with their own job assigned. As a junior staff sometimes, I approach my seniors to ask the things that I want to know in clarity, or I want to know more detail. But I got fully upset as sometimes; I find it hard (they also are) to find time to approach and ask

\section{Barriers in Knowledge Retention}

Issue 1: Participants explained knowledge retention from the perspective of the organization rather than from their own personal perspectives. Knowledge retention poses challenges depending on whether the knowledge is explicit or implicit. To the participants, while tacit knowledge that an individual has accumulated throughout in organizational life is retained in their heads (the memory of individual members), some explicit knowledge is stored in hard and soft forms of documents for retrieval later use. While this storage and retrieval of tacit knowledge held by organizational members does not impose challenges immediately, participants are concerned about the problem of staff turnover in the process of knowledge creation imposed at the department's wider unit level. As Participant $\mathrm{C}$ explained:

Retention of knowledge doesn't seem to have a problem at a glance. Nevertheless, I feel like it is the most important challenge for the knowledge-based organization like our department. Since I join the department, most of our reputable and respectful and qualified staff (who were my former teachers) leave the department for mainly family reasons. I feel very sorry when specialized knowledge is losing together with them. But whatever the reason they leave, the knowledge they accumulated throughout their working life is lost together. Though it seems inevitable, it is a huge loss to me, others (who were committed to learning from them), and the department. We need a good system to keep its knowledge from these people.

Issue 2: Another challenge with knowledge retention is the need for an immediate response from the people who acquired specialized new knowledge. The attempts to keep record the newly learned knowledge of organizational members is to encourage them record-keeping immediately. This is overwhelmingly important in newly acquired knowledge but seldom used, whenever an individual will keep that knowledge in the short-term memory. Unless properly stored, the retrieval of knowledge is feasible, and the value of knowledge will depreciate over time. Participant E's commentary:

Our Organization/department sent to staff (including me) to seminar and workshops. Some workshops are good, but no way to use the knowledge obtained immediately. What happened to me is after some time, everything lost in my mind. When I find it useful later, I searched the docs, but I cannot remember everything anymore. Not only that knowledge was lost to me and for everyone. 


\section{Barriers in Knowledge Sharing}

The barriers to effective knowledge sharing within the department tend to revolve around its culture. While supportive culture facilitates knowledge sharing among members, unfavourable culture prevents cooperation, inhibits trust and enhances the willingness to conceal or withhold knowledge.

Issue 1: Close social relationships are one of the dispensable factors that promote knowledge sharing, as people tend to share their knowledge with those they have a close connection with. The relationships within departments are built due to long-term personal friendships, reciprocal relationships and personal loyalty. Participant B further explained how knowledge sharing can be inhibited:

I am open to obtain knowledge shared by other members, either seniors or juniors. I think some juniors also possess knowledge if they are keen on a particular area of their interest. But their knowledge sharing is restricted to people who they have a close friendship (relationship). To me, it is difficult because the relationship cannot be built within a short period.

Issue 2: While long-term relationships can be a key for sharing valuable knowledge that one accumulated over a long period, knowledge-sharing best occurs within members who have reciprocal relationships, such as an exchange of resources outside the organizational setting. As Participant G disclosed,

Some people tend to have 'give and take' relationship in knowledge sharing (such as exchanging knowledge another person possesses in the speciality or other resources such as time). Every time, I do not have anything to return to some people I want to get shared knowledge from. This expectation for getting reciprocity prevents some people from sharing the knowledge that they possess.

Issue 3: Another challenge in knowledge sharing is the attitude of the people who need to share knowledge. These attitudes are concerned with fear for the loss of power, which prevents knowledge sharing, and a lack of understanding and appreciation for the benefits others could obtain. Knowledge sharing culture cannot flourish as it should because of the inability of people to understand the potential benefits of knowledge sharing in the bigger picture. This is highlighted by Participant F, who states:

As I see, while knowledge sharing is vital, some people cannot see the benefits of knowledge sharing. At a minimum, these people do not appreciate the potential gains other people will obtain from if they share their knowledge. At worse, some people do not support or facilitate the atmosphere where knowledge sharing happens at all as I think they may not respect the people.

\section{Discussion}

According to the findings of the survey, there are strengths and weaknesses of the current situation of the department, concerned about the concept of knowledge management. 
According to Bryson (2004), strengths and weaknesses are primarily concerned with the current situation of the organization, while opportunities and threats/challenges are generally concerned with external factors. In terms of the positives inside of the department, academic staff are well aware of their position and role and responsibilities, and are well-educated, too; there are no illiterate staff in the department as well as they are eager to learn. In addition, as opportunities for learning, the department has been supported from the partners for development. Besides strengths of the department, there are some weaknesses resulting in slow knowledge flow. In fact, since departmental structure is centralized and steep, teaching staff have heavy workloads and departmental policies and standards reflects bureaucratic management process. Moreover, although the department has received funds provided by the government, it is insufficient funding. Thus, even though knowledge management can provide opportunities for achievement of departmental goals and objectives and improving teacher quality as well as benefits in a number of ways, including improved collaboration, better communication among teachers, enhanced their teaching skills, and increased innovation, there have been others that are challenges pertaining to the knowledge generation, knowledge retention, and knowledge sharing to be a successful department.

In the department, there are some challenges of knowledge management process. The major issue in current state of the department is knowledge sharing among teachers. In this case, the most important factor is time constraint, which means that our academic staff could not spend much time towards discussion, exchange of information or getting advice from their colleagues as they have heavy workloads schedule and little time to spend with their colleagues. Other challenges are that some qualified and expert teachers are reluctant to share their work, their knowledge, experiences, and ideas they have created. Moreover, teaching staff usually follow the directions and instructions from the Head of Department or senior teachers in terms of the traditional values of respect and authority so that in some cases, there is lack of opportunities for junior or new teachers to present their new ideas and concepts. Another kind of constraint is an absolute insufficiency of funds to cover the incremental costs associated with information technology for knowledge sharing and retention, and provide research projects for the creation of new knowledge. Thus, Szulanski (1996) pointed out that "the notion of internal stickiness connotes the difficulty of transferring knowledge within the organization" (p. 29). That is why the department's challenges and weaknesses should be regarded as strong indicators for building higher strengths and improving performance.

\section{Recommendations for Improvement in KM Practices}

On the basis of findings of the study, the following recommendations are made:

Recommendation 1: In a nutshell, the department needs to take a pragmatic approach to KM or knowledge strategy, manage the right knowledge for the right purpose, and in the right way, as well as sustain strengths and mitigate challenges in the KM process. Porter (1996) pointed out that "strategy is the creation of a unique and valuable position, involving a different set of activities that can manage strategic issues" (p. 68). As such, the department needs to assess its knowledge position and develop a knowledge map, i.e. a useful tool for presenting the repositories of knowledge and representing the flow 
of knowledge in an organization. Therefore, in the department, a knowledge map should be created to perform a knowledge analysis and access knowledge, identify and reduce knowledge gaps, and ensure that all members participate in sequential KM processes. Nevertheless, the insights gained from the interviews illuminate the agenda to set forth the following recommendations. These are provided in light of the participants' commentary regarding what they perceive to be substantive barriers.

Recommendation 2: One way to lessen the major barriers in knowledge acquisition is first to provide enough time and space (physically or mentally) to pursue self-directed learning. Staff would require a certain amount of time to apply self-directed learning. However, if academic staff are too busy performing their daily tasks (over workload), there will not be adequate time for self-directed learning. One way to address this issue is to build a balance between teaching and learning in the bargaining agreement. Moreover, observing peer classrooms and attending conferences can enhance self-directed learning. By providing these activities, knowledge can be created throughout the department and acquired by searching and sourcing from the external environment. Also, academic staff should be given autonomy because self-directed learning is amplified when people are committed to learning the areas they have a special interest in. Doing so would facilitate their self-directed learning as staff are more committed to doing things they are motivated or inclined to.

Recommendation 3: Where knowledge retention is concerned, attracting and retaining high-quality academic staff is vital. It can also contribute to mitigating the loss of knowledge caused by the turnover of staff who possess specialized knowledge. Wellorganized succession planning is the key to employing holding assumptions that all key staff may come and go. As such, it is crucial to identify the areas where key knowledge has the potential to leak and where it is less widespread among most of the members. To attract and retain well-prepared and experienced teachers, motivation is critical. For example, intrinsic factors such as job satisfaction, recognition and personal growth tend to attract teachers into the teaching profession, while fulfilling and supporting extrinsic factors such as suitable working conditions, salaries and benefits, job security, and opportunities for professional development are important in order to retain them in the profession. Turnover of qualified academic staff results in knowledge loss. In this case, although explicit knowledge is easy to catalogue, e.g. saving the files, implicit knowledge can be more difficult because it is about experience and context. Since it includes personal relationships, the transfer of implicit knowledge is difficult. Thus, qualified teachers who resigned or retired from their posts should be considered for placement in a substantive post. Bringing knowledge back from the past and trying to pass it on is a good way to retain tacit knowledge for teachers remaining in the profession. By doing so, tacit knowledge of qualified teachers can be retained within the department. In addition, IT knowledge has become a major step in explicit knowledge retention. The department can expand the IT knowledge of academic staff by collaborating with key partnerships which could able to support financial aids for departmental development. The requirement is to establish effective collaboration between the department and effective research partnerships/research institutes.

Recommendation 4: To mitigate knowledge sharing barriers, socialization needs to be emphasized by developing trust, sharing of experiences, joint activities, and day-to-day interaction; otherwise, the lack of social relations and low realization of others' knowledge and value could be a potential knowledge sharing barrier. Knowledge 
can exist in an individual brain that remembers what they have learned, or in the collective through the interactions of groups of individuals, meaning the knowledge needed in a workplace environment can be accessed individually and collectively. The department needs to utilize team-based practices so that all members of the department can socialize and know and understand each other at a deeper personal level and foster sharing of their thoughts and positive attitudes towards each other.

Recommendation 5: Developing team-based practices will minimize the problem associated with culture in knowledge sharing and reduce the hierarchical barriers of large bureaucratic organizations so that knowledge sharing may occur. It is important to understand the knowledge dynamics and how formal and informal relationships coexist within the same organizational social structure. More than this, to create a knowledge-sharing culture, polices should be initiated and implemented: incentives to provide a reward, be it either intrinsic or extrinsic, to those who share knowledge and facilitate a knowledge-sharing culture within the department.

\section{Conclusion}

Knowledge is the most valuable resource to maintain the growth and survival of organizations and their sub-units. In this regard, to a knowledge-based organizational unit, such as an academic department of a university, effective KM presents a vital role in implementing KM process involving knowledge creation, retention, and sharing and minimizing the underlying barriers at each level of the KM process. However, effective knowledge strategy benefits can be hard to realize as organizational units encounter the barriers manifest at different levels, such as individual and organizational within micro $\mathrm{KM}$ processes. Individual factors, such as time and resource constraints, underpin knowledge acquisition. The organizational factors such as staff turnover affect knowledge retention, and both individual and organization-level barriers such as subgroups and politics manifest in the knowledge sharing process. If the Commerce Department can establish knowledge strategies (for instance, socialization and teambased practices) to mitigate individual and organizational barriers, it can unleash ample opportunities for capturing, sharing, and integrating knowledge to enhance students' teaching and learning abilities and facilitate the attainment of the organisation's mission and objectives, i.e., the university as a whole.

\section{Acknowledgement}

The authors would like to thank the head of the department Dr Soe Thu for granting to interview academic staff. We would also like to express our sincere gratitude to academic staff who actively participated in the interview. 


\section{References}

Abebe, J. (2016). The effect of knowledge management enablers on sustainable competitive advantage amongst humanitarian agencies in Kenya. SSRN Electronic Journal. Retrieved from https://www.researchgate.net/publication/315376732

Al-Alawi, A. I., Al-Marzooqi, N. Y., \& Mohammed, Y. F. (2007). Organizational culture and knowledge sharing: critical success factors. Journal of Knowledge Management, 11(2), 22-42.

Allard, S. (2004). Knowledge creation. In H. Clyde (Ed.), Handbook on Knowledge Management (pp. 367-379). Location: Springer.

Baskerville. R., \& Dulipovici, A. (2006). The theoretical foundations of knowledge management. Knowledge Management Research \& Practice, 4(2), 83-104.

Ben-Peretz, M. \& Schonmann, S. (1998). Informal learning communities and their effects. In K. Leithwood (Ed.), Organizational learning in schools (pp. 47-66). Lisse, Netherlands: Swets \& Zeitlinger.

Bonaventura, M. (1997). The benefits of knowledge culture. Aslib Proceedings, 49(4), 82-89.

Byrson, J. M. (2004). Strategic planning for public and nonprofit organizations: A guide to strengthening and sustaining organizational achievement (3rd ed.). San Francisco: Jossey-Bass.

Choi, Y.S. (2000). An empirical study of factors affecting successful implementation of knowledge management. Unpublished academic dissertation. University of Nebraska.

Cresswell, J. W., \& Plano Clark, V. L. (2011). Designing and conducting mixed method research (2nd ed.). Thousand Oaks, CA: Sage.

Davenport, T. H., \& Prusak, L. (2000), Working Knowledge: How Organizations Manage What They Know. Boston, MA: Harvard Business School Press.

Drucker, P. F. (1993). Post-Capitalist Society. New York: Harper Business.

Eisenhardt, K. M. (1989). Building theories from case study research. Academy of Management Review, 14(4), 532-550.

Gammelgaad, J., \& Ritter, T. (2000). Knowledge retrieval process in multinational consulting firms. Frederiksberg, Denmark: Danish Social Sciences Research Council. Retrieved from http://web.cbs.dk/departments/int/seminarpapers/JGKnowledge.pdf

Gourlay, S. (2003). The SECI model of knowledge creation: some empirical shortcomings. Paper presented to 4th European Conference on Knowledge Management. England, 18-19 September.

Haggie, K., \& Kingston, J. (2003). Choosing your knowledge management strategy. Journal of Knowledge Management Practice, 4(4), 1-20.

Hislop, D. (2013). Knowledge management in organizations: A critical introduction ( $3^{\text {rd }}$ ed.). UK: Oxford University Press.

Holsapple, C. (2003). Handbook on Knowledge Management. USA: Springer.

Jarnagin, C., \& Slocum, J. W. (2007). Creating corporate cultures through mythopoetic leadership. Organizational Dynamics, 36(3), 288-302.

Kalkan, V. D. (2005). Knowledge management challenges for global business. International Business \& Economics Research Journal, 4(10), 19-28. 
Karamat, J., Shurong, T., Ahmad, N., Waheed, A., \& Khan, S. (2018). Barriers to Knowledge Management in the Health Sector of Pakistan. Sustainbility, 10(11), $1-22$.

Khakpour, A. (2015). Knowledge management in education organizations/opportunities and challenges. Retrieved from https://www.researchgate.net/publication/272886479

King, W. R. (2009). Knowledge management and organizational learning. USA: Springer.

Mahroeian, H., \& Forozia, A. (2012). Challenges in managing tacit knowledge: A study on difficulties in diffusion of tacit knowledge in organizations. International Journal of Business and Social Science, 3(19), 303-308.

McCune, J. (1999). Thirst for knowledge. Management Review, 88(4), 10-12.

McDermott, R., \& O'Dell, C. (2001). Overcoming cultural barriers to sharing knowledge. Journal of Knowledge Management, 5(1), 76-85.

McInerney, C. (2002). Knowledge management and the dynamic nature of knowledge. Journal of the American society for Information Science and Technology, 53(12), 1009-1018.

Mládková, L. (2011). Knowledge management for knowledge workers. Electronic Journal of Knowledge Management, 9(1), 260-267.

Morrinson, E. W. (1993). Newcomer information seeking: Exploring types, modes, sources, and outcomes. Academy of Management Journal, 36 (3), 557-589.

Nadason, S., Saad, R., \& Ahmi, A. (2017). Knowledge sharing and barriers in organizations: A conceptual paper on knowledge-management strategy. IndianPacific Journal of Accounting and Finance (IPJAF), 1(4), 32-41.

Nonaka, I., \& Konno, N. (1998). The concept of" ba": Building a foundation for knowledge creation. California Management Review, 40(3), 40-54.

Nonaka, I., \& Takeuchi, H. (1995). The knowledge-creating company: How Japanese companies create the dynamics of innovation. Oxford: Oxford University Press.

Nonaka, I., Toyama, R., \& Konno, N. (2000). SECI, ba and leadership: a unified model of dynamic knowledge creation. Long Range Planning, 33(1), 5-34.

Oakley, A. (2003). Research evidence, knowledge management and educational practice: early lessons from a systematic approach. London Review of Education, 1(1), 21-33.

O'Toole, P. (2004). Retaining knowledge through organizational action. Adelaide: Flinders University Institute of International Education.

Pan, S. L., \& Leidner, D. E. (2003). Bridging communities of practice with information technology in pursuit of global knowledge sharing. Journal of Strategic Information Systems, 12(1), 71-88.

Patton, M. Q. (2002). Qualitative research and evaluation methods (3rd ed.). Thousand Oaks, CA: Sage.

Petrides, L. \& Nodine, T. (2003). Knowledgement management in education: Defining the landscape. California: ISKME.

Porter, M. (1996). What is strategy? Harvard Business Review, 74(6) 61-78.

Riege, A. (2005). Three-dozen knowledge-sharing barriers managers must consider. Journal of Knowledge Management, 9(3), 18-35. 
Sabri, S. M. (2012). The knowledge sharing practices in higher learning institution: implementation of SECI model. Retrieved from https://www.researchgate.net/publication/283622716

Schmitt, A., Borzillo, S., \& Probst, G. (2012). Don't let knowledge walk away: Knowledge retention during employee downsizing. Management Learning, 43(1), 53-74.

Singh, S. (2009). Knowledge management practices and organizational learning in Indian company. International Journal of Business Innovation and Research, 3(4), 363-381.

Swan, J., Newell, S., Scarbrough, H., \& Hislop, D. (1999). Knowledge management and innovation: networks and networking. Journal of Knowledge Management, 3(4), 262-275.

Szulanski, G. (1996). Exploring internal stickiness: impediments to the transfer of best practice within the firms. Strategic Management Journal, 17, 27-43.

Wallace, D. (2007). Knowledge Management: Historical and Cross-Disciplinary Themes ( $2^{\text {nd }}$ ed.). USA: Libraries Unlimited Inc.

Nair, V. B. \& Munusami, C. (2019). Knowledge management practices: An exploratory study at the Malaysian higher education institutions. Journal of Research in Innovative Teaching \& Learning, 1(1), 1-17.

Veer Ramjeawon, P., \& Rowley, J. (2017). Knowledge management in higher education institutions: enablers and barriers in Mauritius. The Learning Organization, 24(5), 366-377.

Verespej, M. (1999). Knowledge management: System or culture? Industry Week, 248 (15), 20-23.

Yin, R. K. (2003). Case study research ( $3^{\text {rd }}$ ed.). Thousand Oaks, CA: Sage.

Yin, R. K. (2009). Case study research: design and methods ( $4^{\text {th }}$ ed.). Los Angeles, Calif: Sage Publications. 